Tropical Journal of Pharmaceutical Research December 2014; 13 (12): 1979-1985

ISSN: $1596-5996$ (print); 1596-9827 (electronic)

(C) Pharmacotherapy Group, Faculty of Pharmacy, University of Benin, Benin City, 300001 Nigeria.

All rights reserved.

Available online at http://www.tjpr.org

Original Research Article

http://dx.doi.org/10.4314/tjpr.v13i12.4

\title{
Preparation and Characterization of Isosorbide Mononitrate Hydrogels Obtained by Free-Radical Polymerization for Site-Specific Delivery
}

\author{
Nazar Muhammad Ranjha ${ }^{1}$, Asadullah Madni ${ }^{2 *}$, Abdullah Abu Bakar ${ }^{1}$, Nuzhat \\ Talib $^{1}$, Saeed Ahmad ${ }^{2}$ and Hassan Ahmad ${ }^{2}$ \\ ${ }^{1}$ Department of Pharmacy, Bahauddin Zakariya University, 60800-Multan, ${ }^{2}$ Department of Pharmacy, The Islamia University of \\ Bahawalpur, 63100-Pakistan \\ *For correspondence: Email: asadpharmacist@hotmail.com
}

\begin{abstract}
Purpose: To prepare and characterize acrylic acid and ethyl cellulose hydrogels of isosorbide mononitrate for site-specific delivery.

Methods: Free radical polymerization method was employed using benzoyl peroxide as initiator and $\mathrm{N}$, $N$ '-Methylenebisacrylamide (MBA) crosslinked copolymer of ethyl cellulose and acrylic acid. Benzyl peroxide and $\mathrm{N}, \mathrm{N}$ '-Methylenebisacrylamide in varying amounts were dissolved in acrylic acid. The two solutions were mixed together to a final weight of $100 \mathrm{~g}$. Hydrogels were evaluated for sol-gel characteristics, diffusion coefficient, and porosity. Hydrogel formation was examined by FTIR while drug loading efficiency study was carried out using $1 \%(w / v)$ drug solution.

Results: Swelling and drug release decreased with increasing acrylic acid and MBA concentrations due to high degree of crosslinking. Increasing acrylic acid content of hydrogel produced a decrease in drug release from 29.89 to $25.79 \%, 75.37$ to $67.87 \%$ and 84.91 to $75.85 \%$ at pH 1.2, 6.5 and 7.5 , respectively. Remarkably, high swelling was observed at higher $\mathrm{pH}$. Gel fraction and porosity results showed that acrylic acid and crosslinker raised gel fraction but reduced porosity, while ethyl cellulose exhibited a reverse effect. FTIR confirmed graft copolymer formation.

Conclusion: Isosorbide mononitrate hydrogels prepared with crosslinked copolymer of ethyl cellulose and acrylic acid can be suitably formulated for targeted delivery of the drug to the small intestine.
\end{abstract}

Keywords: N, N'-Methylenebisacrylamide, Ethyl cellulose, Acrylic acid, Isosorbide mononitrate, Free radical polymerization, Graft copolymer, Site-specific delivery, Hydrogel, $\mathrm{pH}$-sensitive

Tropical Journal of Pharmaceutical Research is indexed by Science Citation Index (SciSearch), Scopus, International Pharmaceutical Abstract, Chemical Abstracts, Embase, Index Copernicus, EBSCO, African Index Medicus, JournalSeek, Journal Citation Reports/Science Edition, Directory of Open Access Journals (DOAJ), African Journal Online, Bioline International, Open-J-Gate and Pharmacy Abstracts

\section{INTRODUCTION}

Hydrogels have gained much importance nowadays towards the site specific and temporal control of drug delivery systems. These are the three dimensional polymeric networks that can swell after taking in a reasonable amount of water [1]. Proteins, peptides and other drugs can be made safely available in the colon using hydrogel as vehicle. Swelling depends upon monomeric composition, extent of cross linking, type of cross linker and $\mathrm{pH}$ of the surrounding fluid $[2,3]$.

Ethyl cellulose $(E C)$ is an inert, biocompatible, non-ionic water insoluble polymer widely used to prepare slow-release formulations of drugs due to its controlled release property [4]. Acrylic acid 
is extensively used in the synthesis of hydrogels due to its ability to combine readily with its own molecules or other monomers [5].

Isosorbide mononitrate is a member of nitrates class act as vasodilator by relaxation of veins causing enhanced venous capacitance and decrease in ventricular preload. It is used for the immediate relief and prophylaxis of angina pectoris. Isosorbide mononitrate is prescribed in dose $20 \mathrm{mg}$ twice daily and its absorption occurs in small intestine [6]. Isosorbide mononitrite shows rapid rate of absorption when it is directly placed into the intestine [7]. Moreover, targeted delivery of drugs reduces side effects, frequency of administration and enhances patient compliance. In present study, Isosorbide mononitrates $\mathrm{pH}$-dependent hydrogel of ethyl cellulose and acrylic acid were for the small intestine targeted delivery.

Polymerization is carried through free radical polymerization and N, N'-Methylenebisacrylamide (MBA) is used as across linker. Different polymeric and monomeric compositions are used along with varying concentrations of cross linking agent. Phosphate buffer solutions of different $\mathrm{pH}$ are used to calculate the effect of concentration of polymer, monomer and crosslinking agent on dynamic and equilibrium swelling. Finally, the hydrogel was characterized by different parameters such as molecular weight between cross link, FTIR, sol gel, diffusion coefficient, solvent interaction parameters and volume fraction of the polymer.

\section{EXPERIMENTAL}

\section{Materials}

Ethyl cellulose (EC, viscosity 40-100 mPas) was purchased from Shanghai Chemical Factory,
Shanghai, China. The monomer, acrylic acid (AAc, purity $99 \%$ ), and cross-linker N, N'Methylenebisacrylamide (MBA) were purchased from Sigma Aldrich. Benzyl peroxide was purchased from Fisher Scientific, UK. Isosorbide mononitrate was received as donation from Valor Pharma, Islamabad, Pakistan. Analytical grade ethanol was purchased from Sigma Aldrich.

\section{Preparation of $\mathrm{pH}$-sensitive EC/AA hydrogels}

The reported method [3] was adopted after necessary modifications. EC was dissolved in ethanol with continuous stirring till it completely dissolved. Benzyl peroxide and N, N'Methylenebisacrylamide, in varying amounts were dissolved in acrylic acid according to the formula in Table 1 with constant stirring. The two solutions were then mixed together with continuous stirring to obtain a homogeneous mixture. Ethanol was then added to the mixture to make the final weight of the solution $100 \mathrm{~g}$. Polymerization was done by placing sample under the stream of nitrogen for $30 \mathrm{~min}$. The tubes were capped and placed in water bath at a temperature of $45^{\circ} \mathrm{C}$ for $1 \mathrm{~h}, 50{ }^{\circ} \mathrm{C}$ for $2 \mathrm{~h}, 52^{\circ} \mathrm{C}$ for $12 \mathrm{~h}, 55^{\circ} \mathrm{C}$ for $6 \mathrm{~h}, 60^{\circ} \mathrm{C}$ for $3 \mathrm{~h}$ and $65^{\circ} \mathrm{C}$ for $3 \mathrm{~h}$. After complete polymerization and gel formation, the tubes were cooled to room temperature and hydrogels in cylindrical forms were removed from the tubes. Each cylinder was cut into discs of $6 \mathrm{~mm}$ length. Extensive washing of these discs with ethanol-water mixture $(50 \%$ $\mathrm{v} / \mathrm{v}$ ) was performed for the complete removal of unreacted material. Finally, the discs were dried first at room temperature and then in a vacuum oven at $45^{\circ} \mathrm{C}$ to a constant weight.

\section{Swelling measurement}

Dynamic and equilibrium swelling behavior of $\mathrm{pH}$ dependent hydrogels was investigated in different solutions of $\mathrm{pH} 1.2$ with $0.1 \mathrm{M} \mathrm{HCl}$ and

Table 1: Composition of EC/AA polymer

\begin{tabular}{lccccc}
\hline $\begin{array}{l}\text { Sample } \\
\text { code }\end{array}$ & $\begin{array}{c}\text { AA/100g } \\
\text { solution } \mathbf{( g )}\end{array}$ & $\begin{array}{c}\text { EC/100g } \\
\text { solution } \mathbf{( g )}\end{array}$ & $\begin{array}{c}\text { EC/AA } \\
\text { (Wt \%) }\end{array}$ & $\begin{array}{c}\text { MBA } \\
\text { (\% of AA) }\end{array}$ & $\begin{array}{c}\text { MBA/100 g } \\
\text { solution (g) }\end{array}$ \\
\hline $\mathrm{P}_{1}$ & 62.5 & 5 & $7.407 / 92.593$ & 0.5 & 0.313 \\
$\mathrm{P}_{2}$ & 62.5 & 7.5 & $10.714 / 89.285$ & 0.5 & 0.313 \\
$\mathrm{P}_{3}$ & 62.5 & 10 & $13.793 / 86.207$ & 0.5 & 0.313 \\
$\mathrm{O}_{1}$ & 50 & 7.5 & $13.043 / 86.957$ & 0.5 & 0.25 \\
$\mathrm{O}_{2}$ & 67.5 & 7.5 & $10 / 90$ & 0.5 & 0.337 \\
$\mathrm{O}_{3}$ & 85 & 7.5 & $8.108 / 91.891$ & 0.5 & 0.425 \\
$\mathrm{~S}_{1}$ & 67.5 & 7.5 & $10 / 90$ & 0.25 & 0.169 \\
$\mathrm{~S}_{2}$ & 67.5 & 7.5 & $10 / 90$ & 0.4 & 0.27 \\
$\mathrm{~S}_{3}$ & 67.5 & 7.5 & $10 / 90$ & 0.65 & 0.439 \\
\hline
\end{tabular}


$0.05 \mathrm{M}$ USP phosphate buffer solutions of $\mathrm{pH} 6.5$ and 7.5. Pre-weighed dry discs of different samples were allowed to swell in the solution of the desired $\mathrm{pH}$. Swollen discs were removed repeatedly from the solution at pre-determined regular intervals of time, weighed after blotting and then placed in the same buffer. Diffusion coefficient represents the amount of substance diffusing across a unit area through concentration gradient in unit time.

\section{Sol-gel analysis}

Un-crosslinked polymer (18 - $30 \%$ ) in the gel of the various formulations (Table 1) was determined by sol-gel analysis. Non washed samples of 3-4 $\mathrm{mm}$ length were used for this purpose. They were dried at room temperature and then in a vacuum oven at $45{ }^{\circ} \mathrm{C}$ to a constant weight.

The non-cross linked polymer was removed from these samples using Soxhlet extraction for $4 \mathrm{~h}$, with deionized water. Samples were again dried at $45{ }^{\circ} \mathrm{C}$ in vacuum oven to a constant weight. Gel fraction was calculated using the following equation.

$$
\begin{aligned}
& \text { Sol fraction }(\%)=\left[\left(\mathrm{W}_{0}-\mathrm{W}_{1}\right) / \mathrm{W}_{0}\right] 100 \ldots \ldots \ldots \\
& \text { Gel fraction }(\%)=100-\text { Sol fraction } \ldots \ldots \ldots \ldots
\end{aligned}
$$

$\mathrm{W}_{0}$ stands for the initial dry weight of the hydrogel and $W_{1}$ represents the weight of extracted dry gel.

\section{Porosity measurement}

For the measurement of porosity, solvent replacement method previously developed by our research group was applied [3]. Briefly, preweighed dried hydrogels were immersed in absolute ethanol overnight and again weighed after blotting off excess ethanol.

\section{FTIR analysis}

Discs of hydrogel samples were crushed with pestle in an agate mortar. The crushed material was mixed with potassium bromide (Merck IR spectroscopy grade) in 1:100 proportions and dried at $40{ }^{\circ} \mathrm{C}$. The mixture was put under a pressure of $65 \mathrm{kN}$ (pressure gauge, Shimadzu) for 2 min to convert it to a semitransparent disk of size $12 \mathrm{~mm}$. The FT-IR spectrum over the wavelength range 4,500-400 $\mathrm{cm}^{-1}$ was recorded using FTIR spectrometer (FT-IR $8400 \mathrm{~S}$, Shimadzu).

\section{Determination of drug loading of hydrogels}

Six samples, which showed maximum swelling, were selected for drug loading and further release studies. The discs were loaded with drug by soaking them in $1 \%(\mathrm{w} / \mathrm{v})$ aqueous solution of isosorbide mononitrate. Drug solution was prepared by dissolving isosorbide mononitrate in water. Discs were allowed to remain in the mixture till equilibrium swelling. Drug loaded hydrogels with maximum swelling were then dried first at room temperature and then in oven at $45^{\circ} \mathrm{C}$ to a constant weight.

\section{Release kinetic analysis of isosorbide mononitrate}

Isosorbide mononitrate release was studied by using dissolution apparatus (Pharma test PT-Dt7, Germany) associated with UV-VIS spectrophotometer (IRMECO, UV-VIS U2020). The dissolution medium consisted of $0.05 \mathrm{M}$ USP phosphate buffer solutions of various $\mathrm{pH}(1.2$, $6.5,7.5)$. The hydrogel disks were placed in 500 $\mathrm{ml}$ of dissolution medium and analyzed at 220 $\mathrm{nm}$. The temperature was maintained at $37^{\circ} \mathrm{C}$. In order to maintain a uniform concentration of drug in the medium, teflon coated stirring bar was stirred at a rate of $100 \mathrm{rpm}$. The dissolution was studied for the drug release up to $12 \mathrm{~h}$. Zero order, First order, Higuchi and KorsmeyerPeppas models were used for the analysis of drug release pattern.

\section{RESULTS}

\section{Effect of $\mathrm{pH}$ on swelling and drug release from EC/AA hydrogels}

This dynamic and equilibrium swelling behavior is presented in Table 2 . The results clearly show that in a medium of lower pKa value than the pKa value of polymer, a less swelling occurred. However, the polymer medium with a higher pKa value caused it to swell more. Table 3 depicts a picture that how swelling and drug release changed in ascending order with the increase of $\mathrm{pH}$ from acidic to basic.

\section{Effect of monomer concentration on swelling and drug release of EC/AA hydrogels}

To investigate the effect of acrylic acid concentration on drug release, samples with different acrylic acid concentration were loaded with drug. It was observed that as acrylic acid content in hydrogel samples $\mathrm{O} 1, \mathrm{O} 2, \mathrm{O} 3$ increased, drug release profile decreased from 
$29.89 \%$ to $25.79 \%, 75.37$ to $67.87 \%$ and 84.91 to $75.85 \%$ at pH 1.2, 6.5 and 7.5 , respectively.

The effect of EC content on the swelling behavior of EC/AA hydrogels in phosphate buffer of $\mathrm{pH}$ $1.2,5.5,6.5,7.5$ (with a constant ionic strength, I $=0.11 \mathrm{M})$ has demonstrate the effect of concentration of polymer on swelling and drug release. At lower $\mathrm{pH}$ (1.2 and 5.5), there was approximately no difference in swelling ratio of three samples.

\section{Effect of cross-linker concentration on swelling and drug release of EC/AA hydrogels}

In Table 2, the effects of three different cross linker concentrations on swelling and drug release are shown. As anticipated, swelling ratio decreased as the concentration of cross linker was raised from 0.25 to $0.65 \%$ of $A A$.

Molecular weight between cross-links (Mc), and solvent interaction parameters $(\chi)$

Molecular weight between crosslinks (Mc) is the molecular weight between consecutive crosslinks and describes the electrolyte or non-electrolyte type of hydrogel. The results shown in Table 3 were obtained based on Flory-Rehner theory [8] which suggests that Mc values increased with swelling. The values of $V_{2} s$ and $\square$, however, increased in all cases. Higher values of $X$ indicate a weak interaction between polymer and solvent. Mc and number of links $\mathrm{N}$ showed an inverse relation with the concentration of $A A, E C$ and cross-linker.

\section{Sol-gel characteristics}

The effect of $A A$ concentrations on the gel fraction of different formulations of EC/AA hydrogel showed that gel fraction increased with increase in the concentration of $A A$ while it decreased when the amount of EC was raised from $5 \mathrm{~g}$ to $10 \mathrm{~g}$, similar behaviour was studied for MBA.

\section{Porosity}

Porosity has been influenced by $A A, M B A$ and $E C$ concentrations. Increasing $A A$ and $M B A$ concentrations resulted in a decrease in porosity due to formation of denser network and increased physical entanglement between acrylic acid and ethyl cellulose. While, increase in the ethyl cellulose concentration resulted in an increased porosity [3].

Table 2: Dynamic and equilibrium swelling coefficient of EC/AA hydrogels using MBA as cross linking agent

\begin{tabular}{lllllllll}
\hline $\begin{array}{l}\text { Sample } \\
\text { code }\end{array}$ & \multicolumn{9}{c}{ Dynamic swelling coefficient } & \multicolumn{4}{c}{ Equilibrium swelling coefficient } \\
\cline { 2 - 9 } & $\mathbf{p H ~ 1 . 2}$ & $\boldsymbol{p H ~ 5 . 5}$ & $\boldsymbol{p H ~ 6 . 5}$ & $\boldsymbol{p H ~ 7 . 5}$ & $\boldsymbol{p H ~ 1 . 2}$ & $\boldsymbol{p H ~ 5 . 5}$ & $\boldsymbol{p H ~ 6 . 5}$ & $\boldsymbol{p H}$ 7.5 \\
\hline $\mathrm{O}_{1}$ & 1.95 & 2.7 & 4.9 & 5.13 & 3.45 & 6.01 & 36.57 & 40.04 \\
$\mathrm{O}_{2}$ & 1.83 & 2.1 & 3.53 & 4.03 & 3.09 & 4.09 & 20.9 & 27.39 \\
$\mathrm{O}_{3}$ & 1.81 & 1.95 & 3.39 & 4.01 & 3.05 & 3.88 & 20.8 & 27.27 \\
$\mathrm{P}_{1}$ & 1.88 & 2.45 & 4.13 & 4.95 & 3.24 & 5.53 & 29.28 & 37.29 \\
$\mathrm{P}_{2}$ & 1.86 & 2.35 & 4.03 & 4.82 & 3.23 & 5.51 & 28.30 & 35.9 \\
$\mathrm{P}_{3}$ & 1.84 & 2.1 & 3.9 & 4.75 & 3.22 & 4.89 & 27.12 & 33.77 \\
$\mathrm{~S}_{1}$ & 1.9 & 2.33 & 3.85 & 4.21 & 3.4 & 5.79 & 31.07 & 37.9 \\
$\mathrm{~S}_{2}$ & 1.87 & 2.13 & 3.4 & 3.97 & 3.19 & 3.9 & 20.7 & 27.13 \\
$\mathrm{~S}_{3}$ & 1.83 & 1.93 & 3.03 & 3.47 & 2.95 & 3.29 & 14.62 & 20.69 \\
\hline
\end{tabular}

Table 3: Flory-Huggins network parameters of EC/AA hydrogel

\begin{tabular}{lcccccc}
\hline Sample code & $\mathbf{V}_{\mathbf{2 , s}}$ & $\boldsymbol{\chi}$ & $\mathbf{M}_{\mathbf{c}}$ & $\mathbf{M}_{\mathbf{r}}$ & $\mathbf{N}$ & $\mathbf{D ~ 1 0}^{\mathbf{5}} \mathbf{( \mathbf { c m } ^ { \mathbf { 2 } } / \mathbf { s } )}$ \\
\hline $\mathrm{P}_{1}$ & 0.019606 & 0.50663 & 53599.38 & 100.545 & 1066.177 & 2.32 \\
$\mathrm{P}_{2}$ & 0.019973 & 0.50676 & 52983.63 & 113.1122 & 936.8331 & 2.86 \\
$\mathrm{P}_{3}$ & 0.022927 & 0.50778 & 38709.6 & 124.8164 & 620.2646 & 2.57 \\
$\mathrm{O}_{1}$ & 0.018007 & 0.50608 & 62806.56 & 121.9661 & 1029.9019 & 2.36 \\
$\mathrm{O}_{2}$ & 0.028000 & 0.50953 & 27804.24 & 110.3967 & 503.7151 & 3.45 \\
$\mathrm{O}_{3}$ & 0.028236 & 0.50977 & 27288.86 & 103.2071 & 528.8175 & 3.58 \\
$\mathrm{~S}_{1}$ & 0.018811 & 0.50636 & 58867.51 & 110.2989 & 1067.4179 & 2.45 \\
$\mathrm{~S}_{2}$ & 0.025559 & 0.50869 & 36061.46 & 110.3577 & 653.53772 & 3.55 \\
$\mathrm{~S}_{3}$ & 0.034251 & 0.51172 & 21374.7 & 110.4559 & 387.0267 & 4.93 \\
\hline
\end{tabular}

Note: V2s = volume fraction of the polymer at swelling equilibrium in phosphate buffer solution, $\boldsymbol{M}_{\boldsymbol{c}}=$ average molecular weight between cross-links, $\mathbf{M r}=$ molar mass of the repeating unit, $\chi=$ solvent interaction parameter, $\boldsymbol{N}$ = cross-linking density, $\boldsymbol{D}=$ diffusion coefficient 


\section{Drug release mechanism}

Values of regression coefficient " $R$ " obtained from samples with variation in acrylic acid contents are presented in Table 4 \& 5. At pH 1.2, release of drug seemed to be first order, because

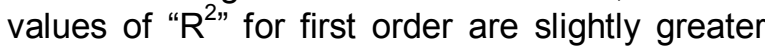
than zero order. However, for $\mathrm{pH} 6.5$ and 7.5, the case is opposite. Here, the release is considered

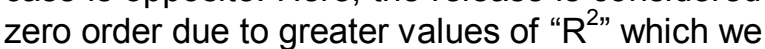
get from zero order release model. Samples with variation in cross-linker showed mixed behavior. Polymers with highest concentration of crosslinker (on all $\mathrm{pH}$ ) and all samples with different cross-linker concentrations showed first order

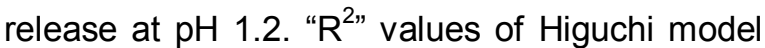
for samples under investigation indicated the diffusion controlled release mechanism. This means that swelling and relaxation of polymer chains are responsible for release mechanism.

\section{DISCUSSION}

Ionization of the carboxylic groups depended on the external $\mathrm{pH}$ and varied with the $\mathrm{pH}$ of the immersion medium. The carboxylic groups at a lower $\mathrm{pH}$ were protonated due to which a few ionized groups in the network exist, and the polymer network remained in a contracted state. As a result, swelling ratios at a lower $\mathrm{pH}$ were insignificant. At a higher $\mathrm{pH}$, elevation in the swelling capability was observed due to the expansion of originally coiled molecules because of electrostatic repulsion. The $\mathrm{pH}$ values in the physiological medium changes from highly acidic conditions in the stomach ( $\mathrm{pH} 1-3)$ to almost neutral values in the small and large intestine (6.37 - 7.49). Hydrogel of the above characteristics can be used for site specific delivery of drugs. The effect of $\mathrm{pH}$ on isosorbide mononitrate release was studied by immersing the isosorbide mononitrate loaded discs in solutions of different $\mathrm{pH}(1.2,6.5$ and 7.5$)$ in dissolution apparatus. Swelling and drug release from gel increased by increasing the $\mathrm{pH}$ of medium.

The effect of acrylic acid (AA) concentration was observed and the sample having low quantity of AA showed highest swelling and vice versa. This was because the hydrogels with lower concentrations of acrylic acid had more vacant spaces for the penetration of water molecules as compared to those having a higher degree of cross-linking due to a higher concentration of $A A$ which resulted in a tougher structure, less swelling and consequently, less amount of drug release [9]. Other reasons which may result in less swelling were the increased viscosity of the release medium due to high AA concentration

Table 4: Effect of acrylic acid concentration on release kinetics of EC/AA hydrogel in various $\mathrm{pH}$ media using MBA as cross linking agent $(0.5 \%$ of $A A)$

\begin{tabular}{|c|c|c|c|c|c|c|c|c|}
\hline \multirow{2}{*}{$\begin{array}{l}\text { Sample } \\
\text { code }\end{array}$} & \multirow[t]{2}{*}{ AA (\%) } & \multirow[t]{2}{*}{$\mathrm{pH}$} & \multicolumn{3}{|c|}{ Zero order kinetics } & \multicolumn{2}{|c|}{ First order kinetics } & \multirow{2}{*}{$\begin{array}{c}\text { Higuchi Model } \\
\mathbf{R}^{2} \\
\end{array}$} \\
\hline & & & $K_{0}\left(h^{-1}\right)$ & $\mathbf{R}^{2}$ & $K_{1}\left(h^{-1}\right)$ & $\mathbf{R}^{2}$ & $K_{2}\left(h^{-1}\right)$ & \\
\hline \multirow{4}{*}{$\mathrm{O}_{1}$} & & 1.2 & 1.748 & 0.9633 & 0.021 & 0.9736 & 0.077 & 0.995 \\
\hline & 50 & 6.5 & 5.109 & 0.996 & 0.102 & 0.995 & 0.216 & 0.991 \\
\hline & & 7.5 & 5.545 & 0.994 & 0.135 & 0.9879 & 0.236 & 0.992 \\
\hline & & 1.2 & 1.807 & 0.995 & 0.021 & 0.997 & 0.084 & 0.9985 \\
\hline \multirow[t]{3}{*}{$\mathrm{O}_{2}$} & 67.5 & 6.5 & 4.624 & 0.9975 & 0.083 & 0.9925 & 0.212 & 0.996 \\
\hline & & 7.5 & 5.247 & 0.9985 & 0.108 & 0.9899 & 0.232 & 0.996 \\
\hline & & 1.2 & 1.808 & 0.993 & 0.021 & 0.9955 & 0.077 & 0.993 \\
\hline \multirow[t]{2}{*}{$\mathrm{O}_{3}$} & 85 & 6.5 & 4.677 & 0.996 & 0.082 & 0.9955 & 0.195 & 0.9894 \\
\hline & & 7.5 & 5.158 & 0.996 & 0.103 & 0.9899 & 0.222 & 0.9904 \\
\hline
\end{tabular}

Table 5: Effect of degree of cross-linking on drug release kinetics of EC/AA hydrogels in various $\mathrm{pH}$ media

\begin{tabular}{|c|c|c|c|c|c|c|c|c|}
\hline \multirow{2}{*}{$\begin{array}{l}\text { Sample } \\
\text { code }\end{array}$} & \multirow{2}{*}{$\begin{array}{c}\text { MBA } \\
\text { content (\%) }\end{array}$} & \multirow[t]{2}{*}{$\mathrm{pH}$} & \multicolumn{2}{|c|}{ Zero order kinetics } & \multicolumn{2}{|c|}{ First order kinetics } & \multicolumn{2}{|c|}{ Higuchi Model } \\
\hline & & & Ko $\left(h^{-1}\right)$ & $\mathbf{R}^{2}$ & $K 1\left(h^{-1}\right)$ & $\mathbf{R}^{2}$ & $K 2\left(h^{-1}\right)$ & $\mathbf{R}^{2}$ \\
\hline & & 1.2 & 1.953 & 0.9808 & 0.024 & 0.9874 & 0.084 & 0.9985 \\
\hline \multirow[t]{3}{*}{$\mathrm{S}_{1}$} & 0.25 & 6.5 & 4.972 & 0.9930 & 0.095 & 0.9960 & 0.212 & 0.9960 \\
\hline & & 7.5 & 5.427 & 0.9940 & 0.124 & 0.9945 & 0.232 & 0.9960 \\
\hline & & 1.2 & 1.874 & 0.9803 & 0.022 & 0.9969 & 0.081 & 0.9985 \\
\hline \multirow[t]{3}{*}{$\mathrm{S}_{2}$} & 0.4 & 6.5 & 4.541 & 0.9955 & 0.084 & 0.9925 & 0.192 & 0.9910 \\
\hline & & 7.5 & 5.356 & 0.9980 & 0.115 & 0.9899 & 0.226 & 0.9905 \\
\hline & & 1.2 & 1.701 & 0.9649 & 0.020 & 0.9726 & 0.072 & 0.9950 \\
\hline \multirow[t]{2}{*}{$\mathrm{S}_{3}$} & 0.65 & 6.5 & 4.291 & 0.9915 & 0.073 & 0.9985 & 0.244 & 0.9955 \\
\hline & & 7.5 & 4.721 & 0.9925 & 0.088 & 0.9990 & 0.287 & 0.9904 \\
\hline
\end{tabular}


and increased ratio of homo-polymerization with respect to graft copolymerization [10].

A significant difference was noted at $\mathrm{pH} 6.5$ and 7.5. This was due to the EC forming intermolecular hydrogen bonds with carboxylic acid groups of $A A$, which influenced the swelling behavior. Swelling ratios slightly decreased with increasing amount of EC but the decrease was insignificant $(p<0.05)$. The hydrophobic nature and an increased amount of EC may be responsible for the decreased swelling [11,12]. The complex structures and denser networks between EC and AA through intermolecular hydrogen bonding were formed due to increased amount of EC. These interactions lowered the ability of hydrogel to form hydrogen bonding with water, due to which water diffusion into the gel was reduced.

Cross-linking density depends largely on the concentration of cross-linking agent. The higher the concentration of cross-linker, the denser will be the networks which result in the production of a decreased mesh size [11]. Hence, there will be less space for water to enter into the hydrogel. Mobility of the polymer chain is also hindered by heavy cross-linking. These factors are responsible for producing a harder and tighter structured hydrogel with lesser swelling. If crosslinked density is higher, then Mc will be lower. When the concentration of monomer and crosslinker rises, cross-linked density increased and as a result the value of Mc decreased. The hydrogels which polymerized in the presence of excess solvent exhibit a higher degree of cyclization, resulting in the formation of a network with low cross-linking density [13].

Increase in gel fraction due to higher concentrations of monomer and cross-linker was the result of more extensive cross-linking as compared to the samples containing lower amounts of these ingredients. On the other hand, increased concentration of ethyl cellulose, solution became more viscous which hindered the movement of free radicals during polymerization. Gel fraction is dependent on cross-linking which in turn also depends on movement of free radicals [14]. As a result, less gel structure formed and sol fraction increased instead of gel fraction.

Ethyl cellulose increases the viscosity of solution which reduces the movement of free radicals leading to impaired polymerization with low cross-linking density. Viscous solution also prevents the bubbles from escaping from the solution resulting in higher porosity due to formation of interconnected channels.
FTIR results showed the appearance of a new band at $1701 \mathrm{~cm}^{-1}$ for EC/AA due to carbonyl stretching. It gives an evidence of the formation of a graft copolymer which indicated that hydrogels were formed due to polymerization of monomers and hence it is evident that hydrogels were successfully prepared for $\mathrm{pH}$ dependant delivery of drug.

\section{CONCLUSION}

Ethyl cellulose and acrylic acid $\mathrm{pH}$-dependent hydrogels were successfully prepared by free radical polymerization. Their swelling kinetics and drug release demonstrated a $\mathrm{pH}$-dependent behavior. As expected, increase in cross-linker concentration resulted in a reduction of their swelling and drug release. The hydrogels are a potential carrier for controlled release and sitespecific delivery of the drugs.

\section{ACKNOWLEDGEMENT}

The authors acknowledge Bahauddin Zakariya University, Multan, Pakistan for providing financial and technical support for this work.

\section{REFERENCES}

1. Peppas NA, Bures $P$, Leobandung $W$, Ichikawa $H$. Hydrogels in pharmaceutical formulations. Eur $J$ Pharmaceut Biopharmaceut. 2000; 50: 27-46.

2. Ranjha NM. Swelling behaviour of $\mathrm{pH}$-sensitive cross linking poly (vinyl acetate-co-acrylic acid) hydrogels for site specific drug delivery. Pak J Pharm Sci. 1999; 12: 33-41.

3. Ranjha NM, Doelker E. pH sensitive noncross linked poly (vinyl alcohol-co-acrylic acid) hydrogels for site specific drug delivery. Saudi Pharm J. 1999; 7: 137143.

4. Rekhi GS, Jambhekar SS. Ethyl cellulose a polymer review. Drug Dev. Pharm. 1995; 21: 61-77.

5. Devine D, Higginbotham C. Synthesis and characterization of chemically cross linked $\mathrm{N}$ vinylpyrrolidone (NVP) based hydrogels. Eur Polym J 2005; 41: 1272-1279.

6. Katzung BG. Basic and clinical pharmacology, 10th edn, McGraw Hill Professional, 2006; 191 p.

7. Kramer WG. Absorption of isosorbide-5-mononitrate at specific sites in the gastrointestinal tract. J Clin Pharmacol 1994; 34(12): 1218-21.

8. Yin L, Fei L, Cui F, Tang C, Yin C. Superporous hydrogels containing poly (acrylic acidcoacrylamide)/O-carboxymethyl chitosan interpenetrating polymer networks. Biomaterials 2007; 28: 1258-1266. 
9. Singh B, Sharma V. Design of psyllium-PVA-acrylic acid based novel hydrogels for use in antibiotic drug delivery. Int J Pharmaceut 2010; 389: 94-106.

10. Li X, Wu W, Wang J, Duan Y. The swelling behavior and network parameters of guar gum/poly (acrylic acid) semi-interpenetrating polymer network hydrogels. Carbohyd Polym2006; 66: 473-479.

11. Pourjavadi A, Mahdavinia GR. Superabsorbency: $\mathrm{pH}$ Sensitivity and Swelling Kinetics of Partially Hydrolyzed Chitosan-g-poly (Acrylamide) Hydrogels. Turk J Chem 2006; 30: 595-608.
12. Ni B, Liu M, Lu S. Multifunctional slow-release urea fertilizer from ethylcellulose and superabsorbent coated formulations. Chem Engr J 2009; 155: 892898.

13. Elliott JE, Macdonald M, Nie J, Bowman CN. Structure and swelling of poly (acrylic acid) hydrogels: effect of $\mathrm{pH}$, ionic strength, and dilution on the cross linked polymer structure. J Polymer 2004; 45: 1503-1510.

14. Ajji Z, Othman I, Rosiak JM. Production of hydrogel wound dressings using gamma radiation. Nucl Instr Methods Physics Res B 2005; 229: 375-380. 